\title{
Age and gender of informal carers: a population-based study in the UK
}

\author{
Lena Dahlberg PhD ${ }^{1}$, Sean Demack BSc $^{2}$ and Clare Bambra PhD ${ }^{3}$ \\ Centre for Research and Evaluation, Sheffield Hallam University, UK, ${ }^{2}$ Social Science \& Law, Sheffield Hallam University, \\ UK, and ${ }^{3}$ Centre for Public Policy \& Health, School for Health, Wolfson Research Institute, University of Durham, UK
}

\author{
Correspondence \\ Clare Bambra PhD \\ Centre for Public Policy \& Health \\ School for Health \\ Wolfson Research Institute \\ University of Durham \\ Queen's Campus \\ Stockton-on-Tees TS17 6BH \\ UK \\ E-mail: clare.bambra@durham.ac.uk
}

\begin{abstract}
This paper identifies variations in the age and gender characteristics of informal carers in the UK. The paper is based on the Individual Sample of Anonymous Records, a 3\% random sample of the 2001 UK Census. The sample size was 1825595 . Of this sample, $10 \%$ were reported to be carers. The analysis shows that informal caregiving is systematically linked with both age and gender. Caregiving increased with age until reaching a peak in the 45-59 age group, in which almost $20 \%$ were carers. Similarly, the amount of time spent caregiving increased with age, with the highest levels of caregiving commitment in people aged $80-89$ years. Regarding gender, $11.3 \%$ of women were carers compared to $8.6 \%$ of men and overall women committed more time to caregiving than men. However, this pattern was reversed in later life $(70+)$, where there was a higher proportion of carers and greater time commitment to caregiving amongst men. While the predominance of women as informal carers has been well reported, the importance of men as informal carers in old age is much less commented upon. This study thus suggests that informal caregiving is most prevalent in groups of the population that, according to previous research, may experience most strain from doing so: elderly people who may be frail and often are in a spousal relationship with the care-recipient, and middle-aged women with multiple roles. Therefore, it is of great importance that their particular needs and circumstances are fully taken into account both in the development of formal support and when information about available support is targeted.
\end{abstract}

Keywords: elderly people, gender, informal care, UK census

Accepted for publication 18 January 2007

\section{Introduction}

In recent years, there has been a renewed interest in family caregiving across developed countries, and it has been recognised that families and other informal relations make considerable contributions to the care of elderly people and people with long-term ill health or a disability (e.g. European Commission 2002, WHO 2002). The UK General Household Survey in 2000 estimated that one in six people aged 16 years or over is caregiving for a sick, disabled or elderly person, and one in five households contains a carer (Maher \& Green 2002), while the UK Census in 2001 showed that there are 5.9 million informal carers in the UK (Office for National
Statistics 2006b). The term 'informal carer' - or 'family

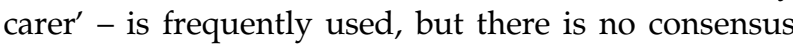
among researchers, policy-makers, service-providers, carers and cared-for persons as to what constitutes an 'informal carer' (for a discussion, see Borgermans et al. 2001). In the UK 2001 Census, 'informal carers' was defined as 'people who provide unpaid care for family members, neighbours or others who are sick, disabled or elderly' (Office for National Statistics 2006b).

Cutbacks in statutory care for elderly people, together with a general promotion of care in the community rather than in residential settings, mean that the pressure on relatives to provide care is likely to increase (e.g. Davies 1995, Payne et al. 1999, Hirst 2001). At the same time, 
demographic changes with ageing populations (Kinsella \& Velkoff 2002, European Commission 2004) mean that the pool of informal carers is declining relative to the increased demand for the care of elderly people (cf. Pickard et al. 2000, Myles 2002, Pflüger 2004). Another important factor in the future potential of informal family caregiving is the experience of caregiving, often described in terms of burden, stress and strain (see George 1994, Chappell \& Reid 2002, Hunt 2003).

Due to the major contribution of informal carers and the impositions related to caregiving, carers' interests need to be acknowledged by policy-makers. Nevertheless, it is only recently that support for carers has started to become regulated by law. In the UK, the government has announced a shift in practice towards a greater recognition of carers with accompanying legislation such as the Carers (Recognition and Services) Act (HMSO 1995); the Carers and Disabled Children Act (HMSO 2000); and the Carers (Equal Opportunities) Act (HMSO 2004). Until 2000, US federal public policy did not explicitly recognise the service needs of carers (Feinberg \& Newman 2004). Then, the National Family Caregiver Support Program was passed under amendment of the Older Americans Act (Administration on Aging 2004). In Australia, the government has recently released a Caring for Carers Policy to better acknowledge carers and address their needs (Department of Disability, Housing \& Community Services 2003). However, regulations in law do not necessarily mean that carers are provided with appropriate support. For example, under the Social Service Act of 2002, Swedish local authorities are by law only recommended to support and relieve carers (Government Offices of Sweden 2002) indicating the weakness by which support is regulated in the Nordic countries (Sand \& Szebehely 2005).

It is essential that the continued development and provision of support meet the actual need of carers and acknowledge the variations between different groups of carers. In terms of research, it is important therefore to examine 'subgroups of carers for their special needs and experiences rather than considering them undifferentiated members of a homogenous group of informal carers' (Navaie-Waliser et al. 2001, p. 733).

In this context, it is perhaps surprising that researchers have rarely discussed differences between older and younger carers, and why caregiving by an older person is essentially different from caregiving by people of a younger age. Older carers can be expected to differ from younger carers in a number of ways: they are more likely to be frail and in poor health themselves and may therefore suffer more from providing care (cf. van Exel et al. 2005). Furthermore, caregiving for a spouse - as is the case for many older carers (Warner \& Wexler 1998) - benefits both carer and care-recipient, rather than care-recipient alone (Thorsen \& Dyb 1993). This means that if the caregiving cannot be upheld, the carer's own lifestyle and the continuity of the marital dyad are threatened (Miller 1990).

Previous research has tended to focus on gender differences in caregiving, suggesting that women carry out more care and care of higher intensity, but that there are no gender differences amongst those aged 65 years or over (e.g. Ingersoll et al. 1996, Maher \& Green 2002), and that amongst spouse carers, men play an equally important role (Hirst 2001). Still, it has been argued that more attention should be given to gender in caregiving (see Hunt 2003).

\section{Purpose}

The purpose of this paper is to identify age and gender variations amongst informal carers in the UK. Differences will be studied in respect to the proportions of carers in these groups and the amount of time they spend on informal care. Furthermore, interactions between age and gender will be examined.

\section{Methods}

The UK Census is a multipurpose decennial crosssectional survey that collects information on a range of topics from individuals and households in the UK (Office for National Statistics 2005, 2006a). The Census is administered as a postal survey to all UK households and in 2001 the response rate was $94 \%$ with $6 \%$ imputed (Cathie Marsh Centre for Census \& Survey Research 2005). This study utilises data on carers from the Individual Sample of Anonymous Records (SAR), a 3\% stratified simple random sample of the 2001 UK Census (stratified by geographic enumeration districts; for further details, see www.ccsr.ac.uk/sars/guide/2001/sampling.html). SAR data were accessed via the Cathy Marsh Centre for Census and Survey Research (www.ccsr.ac.uk/sars/). The sample size was 1825 595. For the current study, we extracted information on carers relating to the prevalence of caregiving and the number of hours spent caregiving (see Box 1) as well as their age and gender.

Univariate age and gender distributions were calculated for both care provision and amount of time spent caring. Logistic regression was then used to examine any interaction of age and gender in terms of the composition of the carer population (Hosmer \& Lemeshow 2000, Tabachnick \& Fidell 2001). Differences in the amount of time spent caregiving by different age groups were also examined using logistic regression. All analysis was conducted with SPSS version 13. In both cases the outcome was modelled using three explanatory terms: 
Respondents were asked about the time spent caregiving in a typical week 'Do you look after, or give any help or support to family members, neighbours or others because of long-term physical or mental ill health or disability, or problems related to old age? (Do not count anything you do as part of your paid employment)' and respondents could choose from four options: No; Yes, 1-19 hours a week; Yes, 20-49 hours a week; Yes, 50+ hours a week.

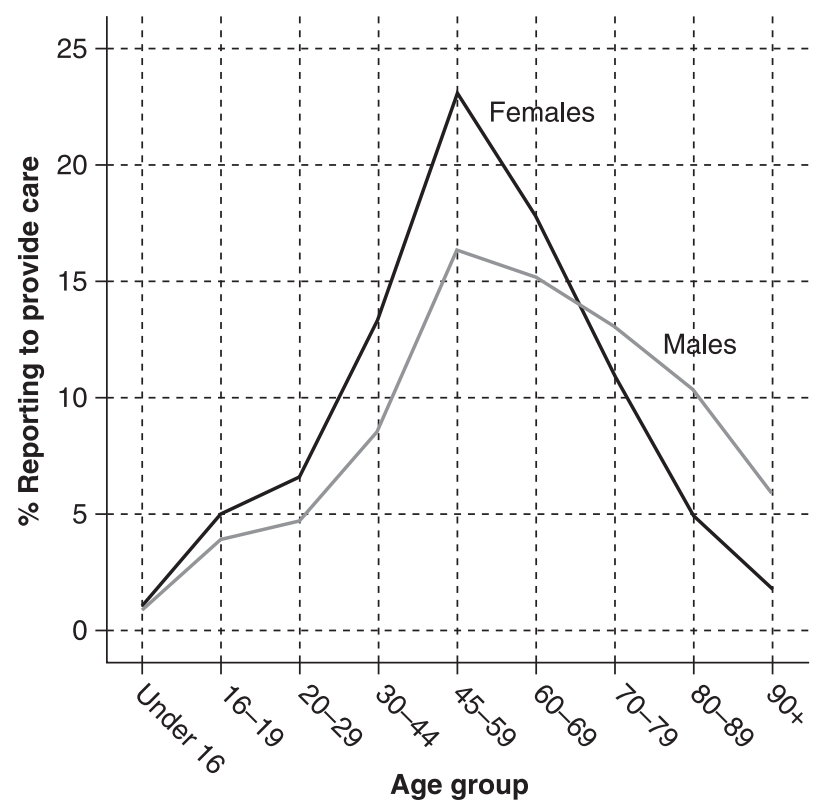

Figure 1 Percentage of people reporting to be carers (by age group for each gender).

gender, age-group and the gender*age-group interaction term. Deviation dummy codings, rather than the more common indicator coding, were adopted for all explanatory variables. This was because a clear reference group within the age-group variable was not evident (for further details on deviation dummy coding, see Hutcheson \& Sofroniou 1999).

\section{Results}

Of the SAR sample, $10 \%$ were reported to be carers (182 664). Caregiving was systematically linked with age (Figure 1). Participation in caregiving was found to increase with age until it reached a peak at age ' $45-59$ ' (almost 20\% of people in this age group were reported to be carers). This was followed by a gradual decrease in older age groups. This pattern was found to be consistent for men and women.

Age was also an important factor in describing variations in the amount of time spent caregiving (see Figure 2). Generally, the amount of time spent caregiving

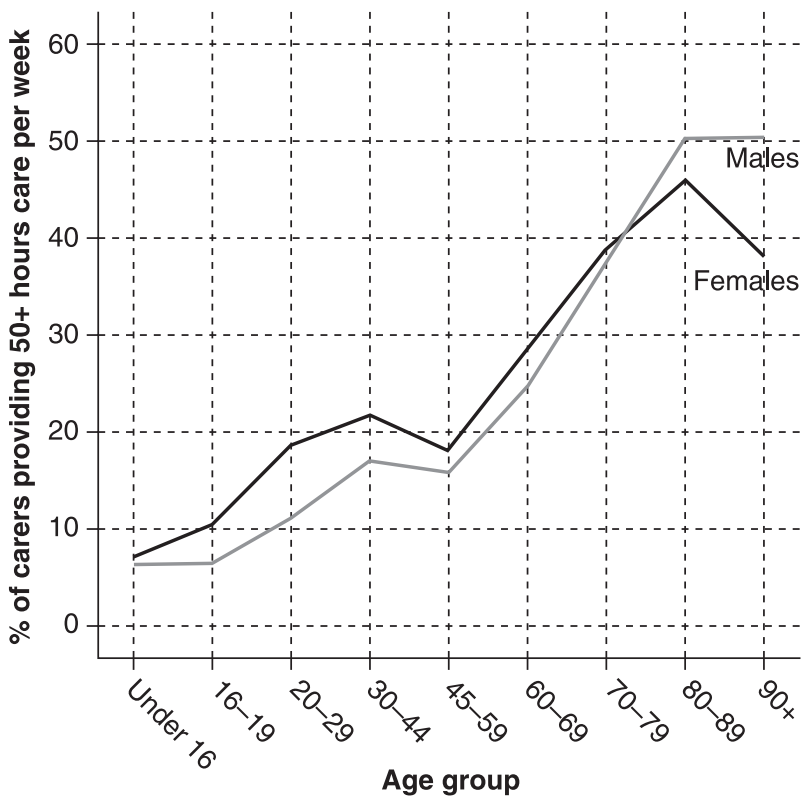

Figure 2 Percentage of carers reporting to care for 50 hours per week or more (by age group for each gender).

increased with age; carers in the younger age groups were less likely to report that they provided care of over 50 hours per week compared to carers who were older. This pattern was generally found to be consistent for both men and women.

There was an association identified between gender and caregiving with $11.3 \%$ (95\% confidence intervals (CI): $11.2-11.4 \%)$ of women being carers compared to just $8.6 \%$ (95\% CIs: 8.6-8.7\%) of men (see Figure 1). Similarly, female carers committed more time to caregiving than male carers: $22.3 \%$ (95\% CIs: $22.1-22.6 \%$ ) of female carers were reported to spend 50 or more hours per week caregiving compared with $20.0 \%$ (95\% CIs: 19.7-20.2\%) of male carers.

An interaction between age and gender was evident in relation to caregiving and time spent caring as illustrated by the crossing lines in the graphs (Figures 1 and 2 , respectively). This interaction was examined more closely through constructing two logistic regression models. Gender, age and an interaction term of gender and age were all found to considerably contribute to both models (Tables 1 and 2, respectively). Comparisons 


\begin{tabular}{|c|c|c|c|c|}
\hline & \multirow[b]{2}{*}{$B$} & \multirow[b]{2}{*}{ Odds ratio } & \multicolumn{2}{|c|}{$\begin{array}{l}95 \% \text { confidence } \\
\text { intervals for odds ratios }\end{array}$} \\
\hline & & & Lower & Upper \\
\hline \multicolumn{5}{|l|}{ Males } \\
\hline Under 16 & -2.113 & 0.121 & 0.115 & 0.127 \\
\hline $16-19$ & -0.561 & 0.571 & 0.545 & 0.598 \\
\hline $20-29$ & -0.382 & 0.682 & 0.662 & 0.703 \\
\hline $30-44$ & 0.270 & 1.310 & 1.283 & 1.337 \\
\hline $45-59$ & 1.002 & 2.724 & 2.673 & 2.776 \\
\hline $60-69$ & 0.914 & 2.495 & 2.438 & 2.553 \\
\hline $70-79$ & 0.734 & 2.084 & 2.028 & 2.141 \\
\hline $80-89$ & 0.474 & 1.606 & 1.538 & 1.678 \\
\hline $90+$ & -0.144 & 0.866 & 0.742 & 1.011 \\
\hline \multicolumn{5}{|l|}{ Females } \\
\hline Under 16 & -1.933 & 0.145 & 0.138 & 0.152 \\
\hline $16-19$ & -0.311 & 0.733 & 0.702 & 0.765 \\
\hline $20-29$ & -0.016 & 0.984 & 0.959 & 1.011 \\
\hline $30-44$ & 0.761 & 2.141 & 2.101 & 2.181 \\
\hline $45-59$ & 1.440 & 4.221 & 4.146 & 4.297 \\
\hline $60-69$ & 1.100 & 3.004 & 2.939 & 3.070 \\
\hline $70-79$ & 0.529 & 1.697 & 1.653 & 1.742 \\
\hline $80-89$ & -0.358 & 0.699 & 0.668 & 0.731 \\
\hline $90+$ & -1.406 & 0.245 & 0.211 & 0.285 \\
\hline Constant & -2.635 & 0.072 & & \\
\hline
\end{tabular}

Table 1 Logistic regression model for reporting to be a carer by age and gender

Data source: Census 3\% Individual Sample of Anonymised Records (SAR).

Model log-likelihood = 108839 ; pseudo $R^{2}=9.2 \%$.

Relative contribution of model components (log-likelihood):

Age: 99 285.7 - 91.2\%; gender: $8.5-0.0 \%$; age* gender: $2990.4-2.7 \%$.

Note: Deviation dummy codings are adopted in the model. For more detail, see Hutcheson

\& Sofroniou (1999, pp. 87-93).

of pseudo $R^{2}$ values (see Menard 1995) show that age and gender combined accounted for a greater proportion of variation in caregiving (about 9\%, see Table 1) than variation in time spent caring (under $4 \%$, see Table 2). Most of this variation was accounted for by age (over $90 \%$ in both models, see Tables 1 and 2). In both models, the influence of gender varied with age.

The value of the constant term in the odds ratio column of Table 1 (0.072) is an average of the true odds of being reported to be an informal carer. The odds ratio value for the age and gender groups indicates whether the group was more likely (value above 1.0) or less likely (value below 1.0) than this average to be reported being an informal carer. The age group most likely to provide care was the ' $45-59$ ' group for both genders (odds 4.2 times higher for women and 2.7 times higher for men - equating to probabilities of 0.24 and 0.17 , respectively). As suggested in Figure 1, women were more likely than men to be a carer up until the age of 70 . Above this age, men were more likely to provide care. The largest gender difference prior to age 70 was located in the ' $30-44$ ' age group, where the odds of women to be carers were 1.6 times higher $(2.141 / 1.310=1.63$, see Table 1). After age 70, the largest gender difference was in the ' $90+$ ' age group, where the odds of men to be carers were 3.5 times higher. Still, it is important to note that the greater number of women in this age group means that the number of female carers aged 90 or more was equal to the number of male carers aged 90 or more, even though the likelihood of being a carer was smaller for women.

Within the caregiving subsample, a gender and age interaction was also present in relation to the time per week committed to caregiving (Table 2). The likelihood of providing over 50 hours care per week increased with age for both men and women. Female carers were more likely than males to provide over 50 hours of care per week in the age groups up to and including ' $60-69^{\prime}$. The widest gender difference was in the ' $20-29^{\prime}$ group where the odds of women providing over 50 hours of care per week were 1.8 times higher. In the ' $70-79$ ' and the ' $90+$ ' age groups there were no significant gender differences. In the ' $80-89$ ' age group, male carers were more likely (odds 1.2 times higher, see Table 2) to provide over 50 hours care per week than female carers. 
Table 2 Logistic regression model for spending over 50 hours per week caregiving by age and gender

\begin{tabular}{|c|c|c|c|c|}
\hline & \multirow[b]{2}{*}{$B$} & \multirow[b]{2}{*}{ Odds ratio } & \multicolumn{2}{|c|}{$\begin{array}{l}95 \% \text { confidence } \\
\text { intervals for odds ratios }\end{array}$} \\
\hline & & & Lower & Upper \\
\hline \multicolumn{5}{|l|}{ Males } \\
\hline Under 16 & -1.414 & 0.243 & 0.201 & 0.295 \\
\hline $16-19$ & -1.380 & 0.252 & 0.210 & 0.301 \\
\hline $20-29$ & -0.777 & 0.460 & 0.421 & 0.502 \\
\hline $30-44$ & -0.285 & 0.752 & 0.716 & 0.791 \\
\hline $45-59$ & -0.383 & 0.682 & 0.652 & 0.714 \\
\hline $60-69$ & 0.182 & 1.199 & 1.139 & 1.262 \\
\hline $70-79$ & 0.786 & 2.195 & 2.077 & 2.320 \\
\hline $80-89$ & 1.315 & 3.726 & 3.423 & 4.055 \\
\hline $90+$ & 1.313 & 3.718 & 2.753 & 5.022 \\
\hline \multicolumn{5}{|l|}{ Females } \\
\hline Under 16 & -1.275 & 0.279 & 0.235 & 0.332 \\
\hline $16-19$ & -0.859 & 0.424 & 0.371 & 0.484 \\
\hline $20-29$ & -0.177 & 0.838 & 0.786 & 0.893 \\
\hline $30-44$ & 0.016 & 1.016 & 0.973 & 1.061 \\
\hline $45-59$ & -0.220 & 0.802 & 0.770 & 0.836 \\
\hline $60-69$ & 0.373 & 1.452 & 1.385 & 1.522 \\
\hline $70-79$ & 0.845 & 2.328 & 2.206 & 2.456 \\
\hline $80-89$ & 1.136 & 3.115 & 2.849 & 3.405 \\
\hline $90+$ & 0.803 & 2.232 & 1.642 & 3.034 \\
\hline Constant & -1.300 & 0.272 & & \\
\hline
\end{tabular}

Note: This is within the subsample reporting to provide care.

Data source: Census 3\% Individual Sample of Anonymised Records (SAR).

Model log-likelihood = 6976; pseudo $R^{2}=3.7 \%$.

Relative contribution of model components (log-likelihood): Age: $6660.0-95.5 \%$; gender: $17.062-0.2 \%$; age*gender: $153.97-2.2 \%$.

Note: Deviation dummy codings are adopted in the model. For more detail, see Hutcheson \& Sofroniou (1999, pp. 87-93).

\section{Discussion}

This study shows that informal caregiving was most common amongst 45- to 59-year-olds. Still, elderly people spent a greater amount of time caregiving than younger people. People over the age of 70 spent the most time on caregiving. This study also shows that the gender pattern of caregiving was related to carers' age. While there was a higher proportion and time commitment of female carers in younger age groups, there was a higher proportion of carers and greater time commitment to caregiving amongst men in older age groups (70+). The importance of older men as informal carers has not often been commented upon. This can have profound influence on interventions and practice, which may not have been developed with this latter group in mind.

By comparison, the predominance of younger women as informal carers confirm previous research (e.g. Ingersoll et al. 1996, Warner \& Wexler 1998, Hirst 2001 Maher \& Green 2002), but they are also more reliable than most previous quantitative UK research, since they are based on a large sample from a high response and nationally representative census survey. However, this study is also subject to some limitations as it is based on a crosssectional survey, with data from 2001; the structured questions were open to differential interpretation by respondents (for example, what is defined as 'informal care' may have been interpreted in different ways by different respondents), and carer status relied on potentially subjective self-report or report by proxy. Furthermore, as with all secondary research, we did not have control over the wording of the questions or the order in which they were asked. Also, the coding of the Individual SAR data file meant that some of the detail of the original responses was lost (e.g. some of the age groups such as $16-19$ or $30-44$ were predetermined for the SAR).

Nonetheless, the age and gender differences in caregiving found in this study are important not only with respect to equality, but also in terms of the implications for carer support. Previous research has shown that there are tendencies that carer burden, such as 
health strain and anxiety, is greater amongst female than male carers (Zarit et al. 1986, Miller 1990, Draper et al. 1995, Payne et al. 1999, Laditka \& Pappas-Rogich 2001), in part due to their multiple roles (Doress-Worters 1994, see though Glaser et al. 2005). This would be particularly evident amongst women of working age, who are likely to also have parental responsibilities. It is also important to note that greater family mobility and higher female employment participation rates (Pflüger 2004) may diminish future potential for women in this age group to participate in informal caregiving.

Similarly, older carers - who in this study are identified as most likely to spend a large number of hours per week providing care - are likely to be in greater need of support since they may be frail themselves. Consequently, they may need consistent support to handle, for example, instrumental aspects of care (Ray \& Street 2005). In addition, even though this study cannot say anything about the relationship between the carer and the caredfor person, previous research suggests that older carers often care for a spouse (Warner \& Wexler 1998) and that spouses have greater risk of higher levels of burden (Draper et al. 1995). At the same time, spouses are the least likely to turn to formal services for help, because of heightened feelings of intimacy and privacy or of fewer resources with which to negotiate care (see Miller 1990). Spouses stand for a substantial and increasing part of the informal caregiving (Bond et al. 1999, Hirst 2001), and are likely to become increasingly important in the future (Pickard et al. 2000).

Taken together, this suggests that informal caregiving is carried out by groups of the population that may experience most strain from doing so, that is, women with multiple roles and elderly people who may be frail and often are in a spousal relationship with the carerecipient. Therefore, it is of great importance that their particular needs and circumstances are fully taken into account both in the development of formal support and when information about available support is targeted. This is beginning to be acknowledged in the UK as recent policy has identified the importance of developing services in response to local needs, focusing on the needs of carers, and emphasising that community care services should be as flexible as possible (Department of Health 2006). Our research suggests that this approach is to be welcomed and that future policy development should continue to acknowledge the diversity of the informal carer population.

\section{Acknowledgements}

The 2001 SARs are provided through the Cathie Marsh Centre for Census and Survey Research (University of Manchester), with the support of the ESRC and JISC. All tables containing Census data, and the results of analysis, are reproduced with the permission of the Controller of Her Majesty's Stationery Office and the Queen's Printer for Scotland.

\section{References}

Administration on Aging (2004) National Family Caregiver Support Program, Older Americans Act. [WWW document]. URL http://www.aoa.gov/prof/aoaprog/caregiver/careprof/ progguidance/resources/FINAL\%20NFCSP\%20Report\%20July22,\%202004.pdf (accessed 23 September 2005).

Bond J., Farrow G., Gregson B.A., Bamford C., Buck D., McNamee P. \& Wright K. (1999) Informal caregiving for frail older people at home and in long-term care institutions: who are the key supporters? Health and Social Care in the Community 7, 434-444.

Borgermans L., Nolan M. \& Philp I. (2001) Europe. In: I. Philp (Ed.) Family Care of Older People in Europe, pp. 1-25. IOS Press, Amsterdam.

Cathie Marsh Centre for Census and Survey Research (2005) Guide to the 2001 SARS [WWW document]. URL http:// www.ccsr.ac.uk/sars/guide/2001/2001sars.doc (accessed 20 June 2005).

Chappell N.L. \& Reid C.R. (2002) Burden and well-being among caregivers: examining the distinction. The Gerontologist 42, 772-780.

Davies B. (1995) The reform of community and long-term care of elderly persons: an international perspective. In: F. Scharf \& G.C. Wenger (Eds) International Perspectives on Community Care for Older People., pp. 21-38. Aldershot, Avebury.

Department of Disability Housing and Community Services ACT Government (2003) Caring for carers policy [WWW document]. URL http://www.dhcs.act.gov.au/pubs/ documents/DHCS \%20Carers\%20Policy.pdf (accessed 23 September 2005).

Department of Health (2006) Carers Grant 2006/07 and 2007/08. [WWW document]. URL http://www.dh.gov.uk/assetRoot/ 04/12/81/98/04128198.pdf (accessed 14 April 2006).

Doress-Worters P.B. (1994) Adding elder care to women's multiple roles: a critical review of the caregiver stress and multiple roles literatures. Sex Roles 31, 597-616.

Draper B.M., Poulos R.G., Poulos C.J. \& Ehrlich F. (1995) Risk factors for stress in elderly caregivers. International Journal of Geriatric Psychiatry 11, 227-231.

European Commission (2002) Feasibility Study - Comparable Statistics in the Area of Care of Dependent Adults in the European Union [WWW document]. http://epp.eurostat.cec.eu.int/ cache/ITY_OFFPUB/KS-CC-03-004/EN/KS-CC-03-004EN.pdf (accessed 27 September 2005).

European Commission (2004) The Social Situation in the European Union 2004 [WWW document]. URL http:// europa.eu.int/comm/employment_social/publications / 2004/keag04001_en.pdf (accessed 10 February 2005).

van Exel N.J.A., Koopmanschap M.A., van den Berg B., Brouwer W.B.F. \& van den Bos G.A.M. (2005) Burden of informal caregiving for stroke patients: identification of caregivers at risk of adverse health effects. Cerebrovascular Diseases 19, 11-17.

Feinberg L.F. \& Newman S.L. (2004) A study of 10 states since passage of the National Family Caregiver Support Program: policies, perceptions, and program development. The Gerontologist 44, 760-769. 
George L.K. (1994) Caregiving burden and well-being: an elusive distinction. The Gerontologist 34, 6-7.

Glaser K., Evandrou M. \& Tomassini C. (2005) The health consequences of multiple roles at older ages in the UK. Health and Social Care in the Community 13, 470-477.

Government Offices of Sweden. (2002) Social Services Act [WWW document]. URL http://www.regeringen.se/content/ 1/c6/04/34/02/9d488738.pdf (accessed 23 September 2005).

Hirst M. (2001) Trends in informal care in Great Britain during the 1990s. Health $\mathcal{E}$ Social Care in the Community 9, 348-357.

HMSO. (1995) Carers (Recognition and Services) Act [WWW document]. URL http://www.opsi.gov.uk/acts/acts1995/ Ukpga_19950012_en_1.htm (accessed 23 September 2005).

HMSO. (2000) Carers and Disabled Children Act [WWW document]. URL http://www.opsi.gov.uk/acts/acts2000/20000016.htm (accessed 23 September 2005).

HMSO. (2004) Carers (Equal Opportunities) Act. [WWW document]. URL http://www.opsi.gov.uk/acts/en2004/ 2004en15.htm (accessed 13 May 2005).

Hosmer D.W. \& Lemeshow S. (2000) Applied Logistic Regression, 2nd edn. John Wiley, New York.

Hunt C.K. (2003) Concepts in caregiver research. Journal of Nursing Scholarship 35, 27-32.

Hutcheson G. \& Sofroniou N. (1999) The Multivariate Social Scientist. Sage, London.

Ingersoll Dayton B., Starrels M.E. \& Dowler D. (1996) Caring for parents and parents-in-law: Is gender important? The Gerontologist 36, 483-491.

Kinsella K. \& Velkoff V.A. (2002) The demographics of aging. Aging Clinical and Experimental Research 14, 159-169.

Laditka S.B. \& Pappas-Rogich M. (2001) Anticipatory caregiving anxiety among older women and men. Journal of Women and Aging 13, 3-18.

Maher J. \& Green H. (2002) Carers 2000. The Stationery Office, London.

Menard S. (1995) Applied Logistic Regression Analysis: Sage Quantitative Applications in the Social Sciences (QUASE), no. 106. Sage, London.

Miller B. (1990) Gender differences in spouse caregiver strain: socialization and role explanations. Journal of Marriage and the Family 52, 311-321.

Myles J. (2002) A new social contract for the elderly?. In: G. Esping-Andersen (Ed.) Why We Need a New Welfare State, pp. 130-172. Oxford University Press, Oxford.

Navaie-Waliser M., Feldman P.H., Gould D.A., Levine C., Kuerbis A.N. \& Donelan K. (2001) The experiences and challenges of informal carers: common themes and differences among whites, blacks and Hispanics. The Gerontologist 41, 733-741.

Office for National Statistics (2006a) Informal Carers Who Live in Households: by Age and Sex, 2001: Social Trends 34 [WWW document]. URL http://www.statistics.gov.uk/statbase/ ssdataset.asp? vlnk=7396\&More $=Y$ (accessed 13 April 2006).

Office for National Statistics. (2005) Census 2001 [WWW document]. URL http://www.statistics.gov.uk/census2001/ default.asp (accessed 20 June 2005).

Office for National Statistics. (2006b) 2001 United Kingdom Sample of Anonymised Records, Individual Licensed File [Computer File] Distributed by the Cathie. Marsh Centre for Census and Survey Research. University of Manchester.

Payne S., Smith P. \& Dean S. (1999) Identifying the concerns of informal carers in palliative care. Palliative Medicine 13, 37-44.

Pflüger K. (2004) Study into the impact of EU policies on family carers. The European Older People's Platform [WWW document]. URL http://www.age-platform.org/AGE/IMG/ pdf/report_EUROFAMCARE.pdf (accessed 27 September 2005).

Pickard L., Wittenberg R., Comas-Herrera A., Davies B. \& Darton R. (2000) Relying on informal care in the new century? Informal care for elderly people in England to 2031. Ageing and Society 20,745-772.

Ray R.A. \& Street A.F. (2005) Who's there and who cares: age as an indicator of social support networks for caregivers among people living with motor neurone disease. Health $\mathcal{E}$ Social Care in the Community 13, 542-552.

Sand A.M. (2005) Informell äldreomsorg samt stöd till informella vårdare - en nordisk forskningsöversikt [Informal care for older people and support for informal carers - a Nordic research overview]. In: M. Szebehely (Ed.) Äldreomsorgsforskning. I Norden: En kunskapsöversikt. [Research on elder care in the Nordic countries: A research overview], pp. 197-241. Nordic Council of Ministers, Copenhagen, Denmark.

Tabachnick B.G. \& Fidell L.S. (2001) Using Multivariate Statistics. Allyn and Bacon, New York.

Thorsen K. \& Dyb H. (1993) 'Er Det Noen Som Bryr Seg?' Uformell Omsorg for Eldre Og Offentlig Støtte Till Omsorgsgiverne. ['Does anybody care?' Informal care for older people and public support for caregivers]. Norsk gerontologisk institutt, Oslo, Norway.

Warner L. \& Wexler S. (1998) Eight Hours a Day and Taken for Granted? Princess Royal Trust for Carers, London [WWW document]. URL http://www.carers.org/downloads/takenfor-granted.pdf (accessed 4 October 2005).

World Health Organisation (WHO) (2002) Current and future long-term care needs. An analysis based on the 1990 WHO study The Global Burden of Disease and the International Classification of Functioning, Disability and Health [WWW document]. URL http://www.who.int/chronic_conditions/en/ltc_needs.pdf (accessed 27 September 2005).

Zarit S.H., Todd P.A. \& Zarit J.M. (1986) Subjective burden of husbands and wives as caregivers: a longitudinal study. The Gerontologist 26, 260-266. 